\title{
TÉCNICAS DE MODELAGEM FLORESTAL EMPREGADAS NA ESTIMATIVA VOLUMÉTRICA DE EUCALIPTO
}

${ }^{1}$ Tiago Alves de Araújo, ${ }^{2}$ Fabrícia Conceição Menez Mota, ${ }^{3}$ Reginaldo Sérgio Pereira, ${ }^{3}$ Éder Pereira Miguel, ${ }^{2} \mid l v a n$ Medeiros Lustosa Júnior

1Graduando em Engenharia Florestal da Universidade de Brasília-UnB/ Departamento de Engenharia Florestal, Faculdade de Tecnologia, Brasília, DF. (tiago15araujo@gmail.com)

2 Doutoranda (o) em Ciências Florestais da Universidade de Brasília

${ }^{3}$ Professor Doutor do Curso de Engenharia Florestal da Universidade de Brasília.

Recebido em: 03/10/2016 - Aprovado em: 21/11/2016 - Publicado em: 05/12/2016 DOI: 10.18677/EnciBio_2016B_095

\begin{abstract}
O objetivo do presente trabalho foi estimar a produção volumétrica de um híbrido clonal de Eucalyptus grandis $x$ urophylla por meio de modelos volumétricos tradicionais e com a utilização de Redes Neurais Artificiais (RNA) do tipo MultilayerPerceptron com algoritmo backpropagation e função de ativação logística, usando o diâmetro e a altura total da árvore como variáveis preditoras para estimar de maneira precisa o volume do povoamento de eucalipto com 23 meses de idade. O modelo de Schumacher e Hall foi o que melhor se ajustou para o presente trabalho na estimativa do volume, porém as redes neurais artificiais foram melhores do que os modelos convencionais.
\end{abstract}

RESUMO

PALAVRAS-CHAVE: Eucalyptus grandis x urophylla, modelos volumétricos, RNA.

\section{TECHNICAL MODELLING OF FORESTRY EMPLOYED IN ESTIMATE EUCALYPTUS VOLUMETRIC}

\begin{abstract}
The objective of this study was to estimate the volume production of a hybrid clone of Eucalyptus grandis $\mathrm{x}$ urophylla through traditional volumetric models and the use of RNA. Artificial neural networks MultilayerPerceptron type with backpropagation algorithm and activation function logistics using the diameter and the total tree height as predictor variables for estimate accurately the volume of a hybrid of eucalyptus with 23 months old. The model of Schumacher and Hall was the best fit for this study to estimate the volume, but the artificial neural networks were better than conventional models.
\end{abstract}

KEYWORDS: Eucalyptus grandis x urophylla, volumetric models, RNA. 


\section{INTRODUÇÃO}

O setor florestal possui grande importância na balança comercial nacional e equivale a $5,5 \%$ do PIB industrial (IBÁ, 2015), sendo responsável pela geração de empregos, renda e arrecadação de tributos (FERNANDES, 2013). Segundo esse autor, o setor é o principal fornecedor de matéria-prima para o desenvolvimento da indústria nacional de base florestal.

Para esse campo é de extrema importância conhecer o volume da madeira seja para a valorização ou para o uso social, ecológico e econômico correto (MIGUEL et al., 2010) assim como o planejamento, ordenamento e o uso da madeira, exigem cada vez mais uma maior precisão na determinação da produção volumétrica.

O volume de madeira pode ser obtido pela aplicação de modelos matemáticos conhecidos no meio florestal como modelos volumétricos (MIGUEL et al., 2014). Primeiramente é estimado o volume individual de cada árvore, em seguida é estimado o volume das parcelas que por sua vez são projetados para hectare e para o povoamento todo (MIGUEL et al., 2010).

Foram criados e testados muitos modelos de volume como o de Spurr, Husch, Meyer dentre outros. O modelo mais usado no setor florestal é de SCHUMACHER \& HALL (1933), este quase sempre apresenta estimativas não tendenciosas, ou seja, não possui erros sistemáticos altos nem baixos (CAMPOS \& LEITE, 2009). Contudo, em algumas situações esse modelo é inferior como no caso do trabalho MIGUEL et al. (2014) que estudando modelos para predição do volume individual em plantio de Eucalyptus urograndis encontraram que o modelo de Takata foi superior ao de Schumacher e Hall.

Com o intuito de aumentar a exatidão para determinar o volume e reduzir os custos surgiram novas técnicas dentre as quais destaca-se as Redes Neurais Artificiais - RNA (GORGENS et al., 2009). As RNAs são sistemas computacionais formados por unidades de processamento simples interligados entre si para exercer uma tarefa (BINOTI et al., 2013).

As RNAs apresentam vantagem em comparação as técnicas de regressão, pois são capazes de ajustar dados com relações não lineares sem especificar o modelo (MARTINS et al., 2016). Além disso, permitem incluir variáveis qualitativas como solo, espaçamento, textura, relevo, clone, dentre outros (BINOTI et al., 2015). As redes neurais artificiais têm sido utilizadas em diversas áreas nas ciências florestais inclusive na modelagem de volume (MIGUEL et al., 2015).

O objetivo do presente trabalho foi estimar a produção volumétrica de um híbrido clonal de Eucalyptus grandis $x$ urophylla por meio de modelos volumétricos tradicionais e com a utilização de RNA.

\section{MATERIAL E MÉTODOS}

O estudo foi realizado em um povoamento de híbrido clonal de Eucalyptus grandis $x$ urophylla com 23 meses, pertencente a Fazenda Água Limpa (FAL), localizada no Distrito Federal, distando $20 \mathrm{~km}$ ao sul da cidade de Brasília (LIBANO \& FELFILI 2006).

A altitude média é de 1100 m e conforme a classificação de Köpen o clima da região é do tipo $\mathrm{Aw}$, sendo caracterizado por duas estações bem definidas (quente e chuvosa) que ocorrem de outubro a abril, e outra (fria e seca) de maio a setembro (NIMER, 1989). A temperatura média é de $22,1^{\circ} \mathrm{C}$ com precipitação média anual de 
1468,6 mm. O solo predominante na área é o Latossolo Vermelho Amarelo, pobre em nutrientes e com alto teor de alumínio (LIBANO \& FELFILI, 2006).

Foi realizada a cubagem rigorosa de 60 árvores do povoamento pelo método destrutivo e o volume real das secções transversais das toras foi calculado de acordo com o método de Smalian. Os dados provenientes da cubagem foram divididos aleatoriamente em dois grupos, um para o ajuste dos modelos (48 árvores) e outro para validação (12 árvores). Foram ajustados cinco modelos para análise volumétrica (Quadro 1). Os modelos lineares foram ajustados pelo programa Microsoft Office Excel e o não linear pelo programa Statistica 13.0 (STATSOFT, INC, 2013).

QUADRO 1. Modelos volumétricos utilizados para o ajuste.

\begin{tabular}{ccc}
\hline Autor & & Modelo \\
\hline Husch & Linear & $\operatorname{LnV}=\beta 0+\beta 1 L n D A P$ \\
Meyer & Linear & $V=\beta 0+\beta 1 D A P+\beta 2 D A P^{2}+\beta 3 D A P H+\beta 4 D A P^{2} H+\beta 5 H$ \\
Spurr & Linear & $V=\beta 0+\beta 1 D A P^{2} H$ \\
Naslund & Linear & $V=\beta 0+\beta 1 D A P^{2}+\beta 2 D A P^{2} H+\beta 3 D A P H^{2}+\beta 4 H^{2}$ \\
Schumacher \& & Não- & \\
Hall & linear & $V=\beta 0 * D A P^{\beta 1} * H^{\beta 2}$ \\
\hline
\end{tabular}

Para análise da estimativa foram calculadas as seguintes estatísticas de qualidade de ajustes: a raiz quadrada do erro quadrático médio (RMSE \%), o erro padrão da estimativa absoluto e em porcentagem (Syx e Syx\%), as Bias e o coeficiente de correlação. Foram feitos também análise da distribuição gráfica dos resíduos dos volumes observados e a relação entre valores observados e estimados. A raiz quadrada do erro quadrático médio RMSE (\%) foi calculada pela seguinte expressão:

$$
\operatorname{RMSE}(\%)=\frac{100}{\bar{y}} * \sqrt{\frac{\sum_{i}^{n}(Y e-Y o)^{2}}{n}}
$$

Em que $n=$ valor total dos dados; $\bar{y}=$ média dos valores observados; $Y e=$ volume estimado; $Y o=$ volume observado. expressão:

O erro padrão da estimativa absoluto e o relativo foram obtidos pela

$$
\text { Syx }=\sqrt{\frac{\left(Y_{o}-Y_{e}\right)^{2}}{n-p}} \quad \text { Syx }(\%)=\frac{\text { syx }}{Y m o} * 100
$$

Em que $S y x=$ erro padrão da estimativa absoluto; $S y x(\%)=$ erro padrão da estimativa relativo; $Y_{o}=$ volume observado; $Y_{e}=$ volume estimado; $Y m o=$ volume médio observado; $n=$ número de observações; $p=$ número de coeficientes. As Bias foram obtidas pelo seguinte cálculo:

$$
B I A S=\sum_{i=1}^{n}\left(Y_{\theta}-Y_{o}\right)
$$

Em que $Y_{\theta}=$ volume estimado; $Y_{o}=$ volume observado. 
O coeficiente de correlação $r_{y \hat{y}}$ foi calculado pela seguinte fórmula:

$$
r_{y \hat{y}}=\frac{n \sum Y_{o} Y_{\varepsilon}-\left(\sum Y_{o}\right)\left(\sum Y_{\varepsilon}\right)}{\sqrt{n \sum Y_{o}^{2}-\left(\sum Y_{o}\right)^{2}} * \sqrt{n \sum Y_{\varepsilon}^{2}-\left(\sum Y_{e}\right)^{2}}}
$$

Em que $r_{y \hat{y}}=$ coeficiente de correlação; $n=$ número de dados; $Y_{o}=$ volume observado; $Y_{e}=$ volume estimado.

Para o modelo logarítmico foi feita a correção utilizando o fator de Meyer que é dado pela expressão:

$$
f . m=e^{0,5 * Q M R}
$$

Em que $f: m=$ fator de correção de Meyer; $Q M R=$ quadrado médio do resíduo.

Foram utilizadas as mesmas árvores do ajuste dos modelos volumétricos para o treinamento das redes (48 árvores) e para validação (12 árvores). As variáveis consideradas foram diâmetro a 1,30 de altura (DAP), altura total e o volume (Tabela 1).

TABELA 1. Características dendrométricas das 60 árvores.

\begin{tabular}{ccccc}
\hline Variável & Mínimo & Máximo & Média & Desvio padrão \\
\hline DAP $(\mathrm{cm})$ & 1,80 & 10,80 & 5,98 & 2,78 \\
Altura total $(\mathrm{m})$ & 2,70 & 14,20 & 7,93 & 2,94 \\
Volume $\left(\mathrm{m}^{3}\right)$ & 0,00 & 0,06 & 0,02 & 0,02 \\
\hline
\end{tabular}

O emprego dos dados com a RNA foi viabilizado pelo software Statistica 13.0 (STATSOFT, INC, 2013). Para a estimativa do volume foram treinadas 1000 redes do tipo MLP (MultilayerPerceptron), constituída por dois neurônios na camada de entrada (DAP e H) e uma camada de saída com um neurônio (Volume) utilizando como algoritmo de treinamento o backpropagation.

O número de neurônios na camada oculta foi otimizado pela ferramenta IntelligentProblem Solver do Statistica 13.0. Contudo, essa ferramenta não permite ao modelador selecionar o critério de parada ficando a cargo do programa estabelecer o fim do treinamento. Os pesos das redes foram gerados aleatoriamente pelo próprio software. A função de ativação empregada na camada intermediária e de saída foi a logística.

A taxa de aprendizagem e o termo momentum foram otimizados pelo IntelligentProblem Solver. Essa ferramenta normalizou os dados em intervalos de 0 a 1. O processo de treinamento foi do tipo feedforward, pelo método supervisionado. Nesse método as variáveis de entrada e saída são indicadas para a rede que utiliza o algoritmo de fluxo de dados unidirecional, sem ciclos (HAYKIN, 2001).

Posteriormente ao processo de treinamento foram retidas as cinco melhores RNAs pelo software. Dentre essas redes foi selecionada uma para a validação dos dados a escolha da RNA foi feita a partir das estatísticas de qualidade e do gráfico do resíduo em porcentagem e da relação entre volume observado pelo estimado.

Foram calculados o erro padrão da estimativa absoluto e em porcentagem (Syx e Syx\%), a raiz quadrada do erro quadrático médio (RMSE \%), as Bias e o coeficiente de correlação $\left(r_{y \hat{y}}\right)$. Em seguida foi feita a análise do desempenho do 
melhor modelo tradicional e da RNA na estimativa do volume. Foram comparadas as estatísticas de qualidade citadas anteriormente e o gráfico de dispersão.

Com os dados do volume real foi feito o teste de Shapiro-Wilks caso os dados das 60 árvores apresentassem distribuição normal os dados da validação do volume real e dos volumes estimados pela RNA e pela regressão seriam submetidos a análise de variância (ANOVA), senão ao teste de Kruskal-Wallis e da diferença agregada DA (\%) para verificar se existia diferença significativa entre eles. Esses testes foram realizados através do programa Microsoft Office Excel pelo software Statistica 13.0 (STATSOFT, INC, 2013).

\section{RESULTADOS E DISCUSSÃO}

Para os modelos volumétricos foram ajustados cinco modelos de simples e dupla entrada. A Tabela 2 mostra os resultados dos estimadores de parâmetro dos modelos volumétricos

TABELA 2. Estimadores de parâmetros obtidos no ajuste dos modelos volumétricos.

\begin{tabular}{ccccccc}
\hline Autor & $\boldsymbol{\beta 0}$ & $\boldsymbol{\beta 1}$ & $\boldsymbol{\beta 2}$ & $\boldsymbol{\beta 3}$ & $\boldsymbol{\beta 4}$ & $\boldsymbol{\beta 5}$ \\
\hline Husch & $-8,38393$ & 2,28087 & - & - & - & - \\
Meyer & 0,00267 & $-0,00049$ & 0,000102 & 0,00032 & $7,6 * 10^{-6}$ & $-0,00094$ \\
Spurr & 0,001738 & $3,6 * 10^{-5}$ & - & - & - & - \\
Naslund & 0,00015 & 0,00030 & $-9,9 * 10^{-6}$ & $2,3 * 10^{-5}$ & $-6 * 10^{-5}$ & - \\
Schumacher e Hall & 0,000117 & 1,70426 & 0,80994 & - & - & - \\
\hline
\end{tabular}

Por meio da Tabela 3 percebe-se que os cinco modelos apresentaram bom desempenho estatístico quanto ao erro padrão da estimativa relativo. MIGUEL \& LEAL (2012) estudando Eucalyptus urophylla registraram valores de erro padrão da estimativa relativo de $13,37 \%, 7,38 \%, 9,18 \%, 8,16 \%$ e $8,72 \%$ para os modelos de Husch, Meyer, Spurr, Naslund e Schumacher e Hall respectivamente.

Os resultados do coeficiente de correlação também foram satisfatórios e esses valores variaram entre 0,9842 e 0,9979. SILVA et al. (2015) ajustando modelos volumétricos para três clones de Eucalyptus em Mineiros em Goiás encontraram $\mathrm{r}_{\mathrm{y} \hat{\mathrm{y}}}$ de 0,9695 para o modelo de Husch e 0,9693 para Schumacher e Hall.

TABELA 3. Estatística de ajuste e precisão dos modelos volumétricos.

\begin{tabular}{cccccc}
\hline Parâmetros & Husch & Meyer & Spurr & Naslund & Schumacher e Hall \\
\hline Syx & 0,00259 & 0,00096 & 0,00141 & 0,00095 & 0,00085 \\
Syx (\%) & 15,44 & 5,73 & 8,43 & 5,69 & 5,06 \\
RMSE (\%) & 15,44 & 5,73 & 8,43 & 5,69 & 5,06 \\
Correlação & 0,9842 & 0,9979 & 0,9952 & 0,9979 & 0,9978 \\
Bias & $-0,8089$ & $-3,40 * 10^{-16}$ & $2,42 * 10^{-17}$ & $4,51 * 10^{-17}$ & 0,0010 \\
\hline
\end{tabular}

Os modelos de dupla entrada (Meyer, Spurr, Naslund e Schumacher e Hall) foram superiores ao de simples entrada (Husch). Esse resultado está de acordo com a literatura visto que os modelos que utilizam o diâmetro e a altura produzem os melhores resultados (BAIMA et al., 2001). A Figura 1 mostra a distribuição gráfica dos resíduos para o ajuste dos cinco modelos. 
Husch

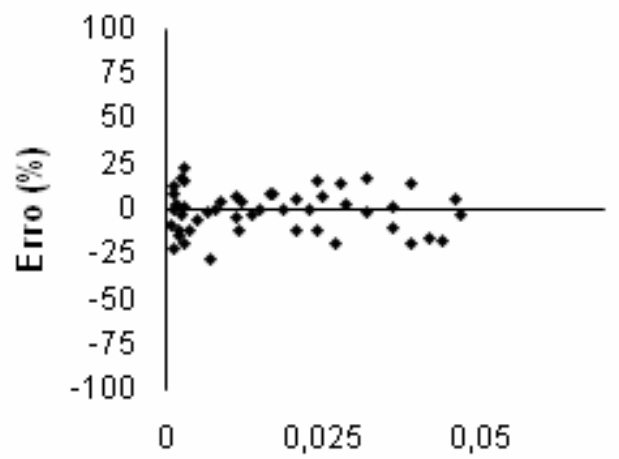

Volume estimado $\left(\mathbf{m}^{3}\right)$

Meyer

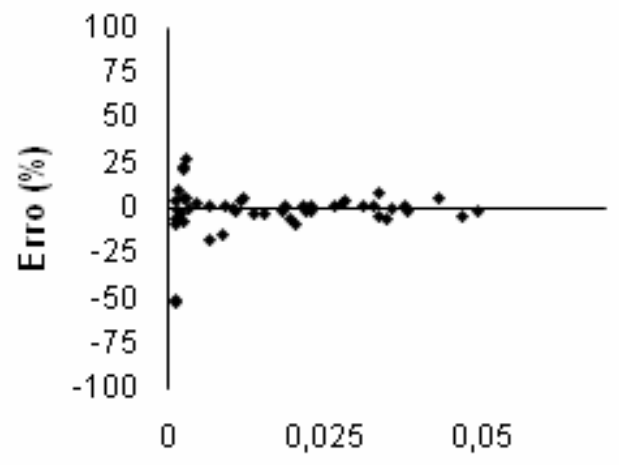

Volume estimado $\left(\mathbf{m}^{3}\right)$

Spurr

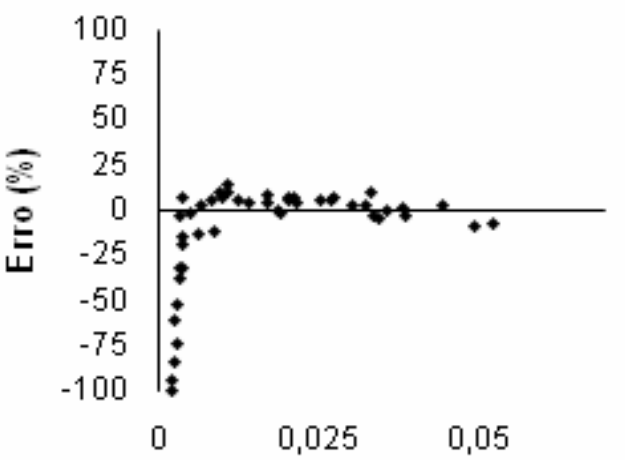

Volume estimado $\left(\mathbf{m}^{3}\right)$
Husch

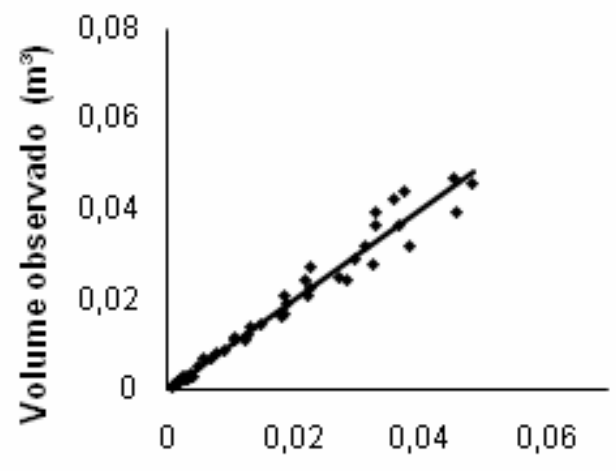

Volume estimado $\left(\mathrm{m}^{3}\right)$

Meyer

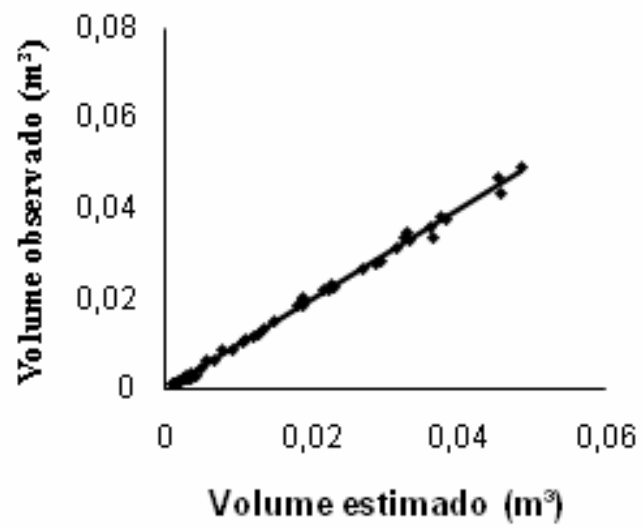

Spurr

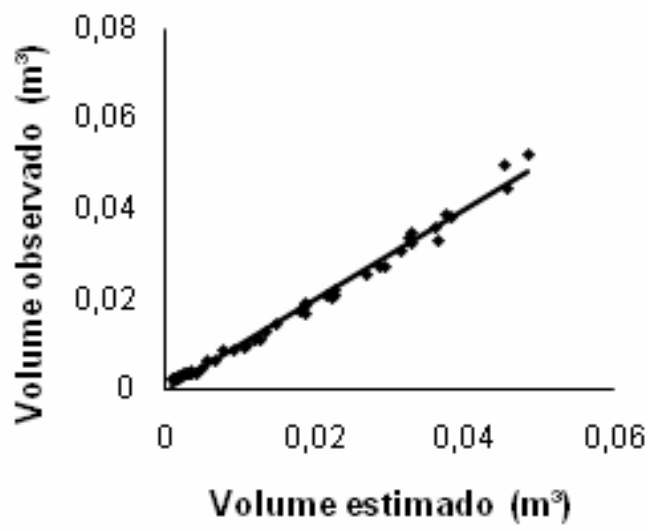



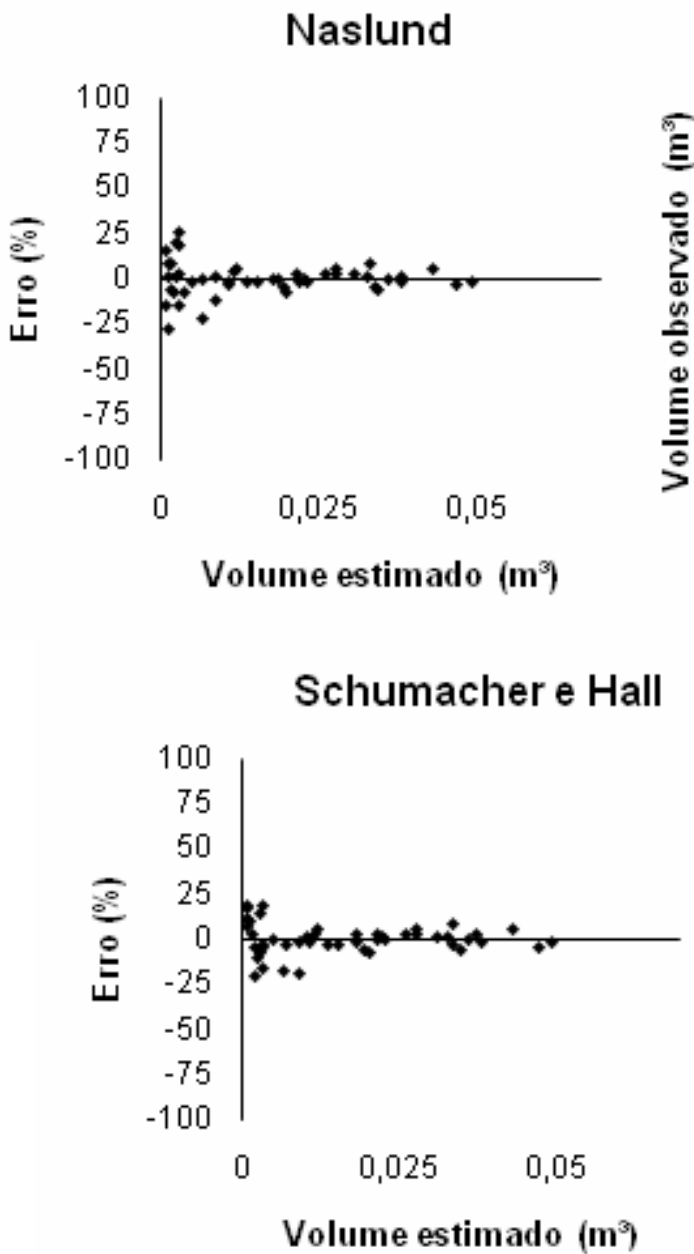
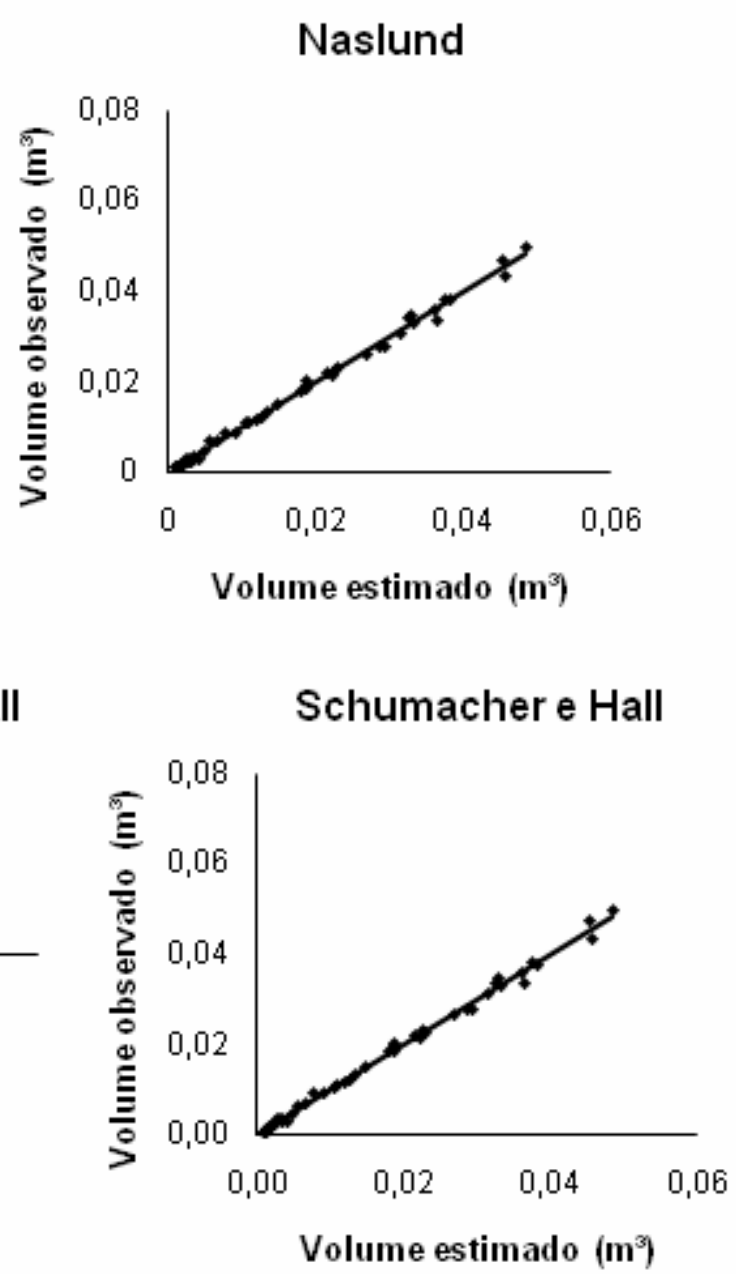

FIGURA 1. Distribuição dos resíduos percentuais em função do DAP e do volume estimado.

O modelo de Husch apresentou uma distribuição residual mais dispersa dos que os outros modelos. Já no modelo de Spurr foi visível a subestimação para volumes menores. Por outro lado, os modelos de Meyer e Naslund apresentaram uma boa distribuição de resíduos, porém os dois foram caracterizados por inflacionar os valores de menor volume.

Já o modelo de Schumacher e Hall mostrou melhor desempenho em comparação ao gráfico de resíduos e as estatísticas de precisão, sendo escolhido para estimar o volume do presente trabalho. SALES et al. (2015) ajustando quatro modelos volumétricos para clone Eucalyptus grandis x urophylla constataram que o de Schumacher e Hall apresentou melhor precisão. A validação dos dados foi feita com o modelo de Schumacher. Na figura 2 estão apresentados os erros percentuais deste modelo para a validação. 
Schumacher e Hall

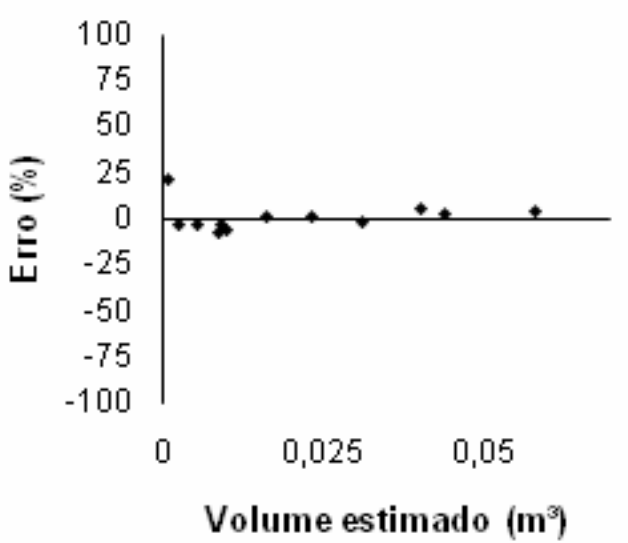

Schumacher e Hall

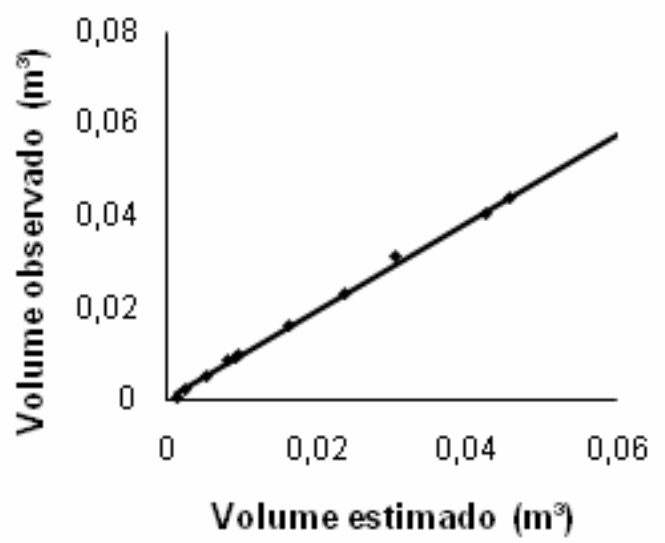

FIGURA 2. Dispersão dos erros percentuais em função dos volumes totais observados e a relação entre valores observados e estimados na validação.

$\mathrm{Na}$ dispersão de resíduos é notório perceber a superestimação e a subestimação do volume. Fato é que na validação, os resíduos ficaram entre erros de $-6,89$ a $21,04 \%$. Com relação as redes neurais a Tabela 4 apresenta as RNAs retiradas no processo de treinamento e as respectivas estatísticas.

TABELA 4. Características das redes neurais artificiais e estatísticas das estimativas do volume.

\begin{tabular}{cccccccc}
\hline $\begin{array}{c}\text { Redes } \\
\text { selecionadas }\end{array}$ & Arquitetura & $\begin{array}{c}\text { Função de } \\
\text { ativação }\end{array}$ & RMSE (\%) & Bias & Syx & Syx (\%) & $\boldsymbol{r}_{\boldsymbol{y} \hat{y}}$ \\
\hline RNA 1 & MLP 2-3-1 & Logística & 5,33 & 0,00136 & 0,00084 & 5,33 & 0,9976 \\
RNA 2 & MLP 2-8-1 & Logística & 6,30 & 0,00243 & 0,00099 & 6,30 & 0,9966 \\
RNA 3 & MLP 2-6-1 & Logística & 5,53 & $-0,00093$ & 0,00087 & 5,53 & 0,9972 \\
RNA 4 & MLP 2-7-1 & Logística & 6,03 & 0,00576 & 0,00095 & 6,03 & 0,9968 \\
RNA 5 & MLP 2-5-1 & Logística & 4,92 & 0,00382 & 0,00077 & 4,92 & 0,9978 \\
\hline
\end{tabular}

A arquitetura MLP, o algoritmo de aprendizagem backpropagation e a função de ativação logística se mostraram apropriados para a estimativa do volume. Isso pode ser observado pelo elevado valor da correlação e os baixos valores de RMSE (\%), Syx, Syx (\%) e Bias.

Uma justificativa para essa arquitetura ter apresentado um bom desempenho é que a configuração MultilayerPerceptron (MLP) possui a capacidade universal de aproximação de funções (HORKIN et al., 1989). Outro ponto de o resultado ser satisfatório é o fato que o modelo de cada neurônio do MLP inclui uma função de ativação não linear, esse requisito foi satisfeito pela função logística.

Apesar da função de ativação logística ser computacionalmente mais lenta de ser avaliada do que a bi-hiperbólica (XAVIER, 2005) essa função apresentou bom resultado. MIGUEL et al. (2016) estimando o volume de um plantio de Eucalyptus urophylla através de Redes Neurais Artificiais com arquitetura MLP usando função de ativação sigmoidal registraram valores de RMSE (\%) de 1,75 e 2,22 e correlação 
$\left(r_{y \hat{y}}\right)$ de 0,989 e 0,994. A Figura 3 apresenta a análise gráfica dos erros percentuais para o treinamento.

RNA-1

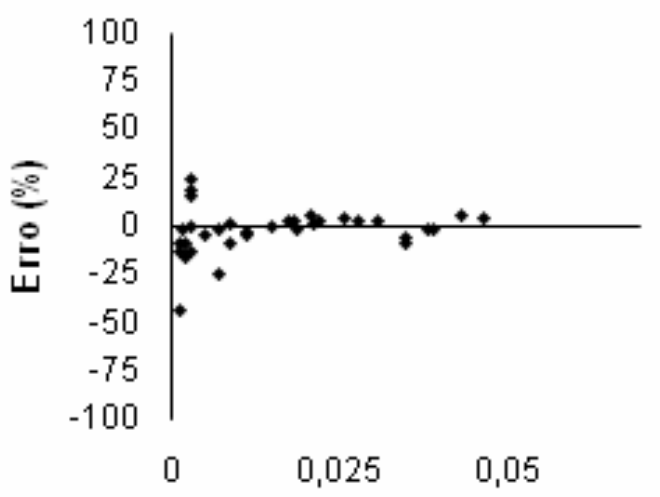

Volume estimado $\left(\mathrm{m}^{3}\right)$

RNA-2

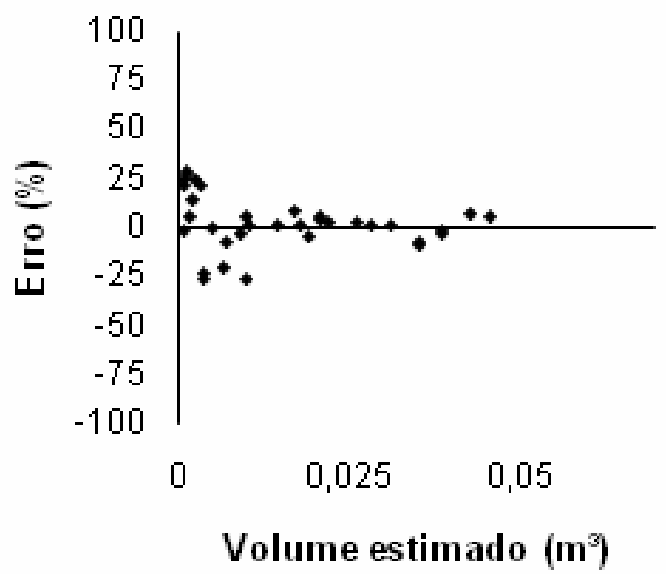

RNA-3

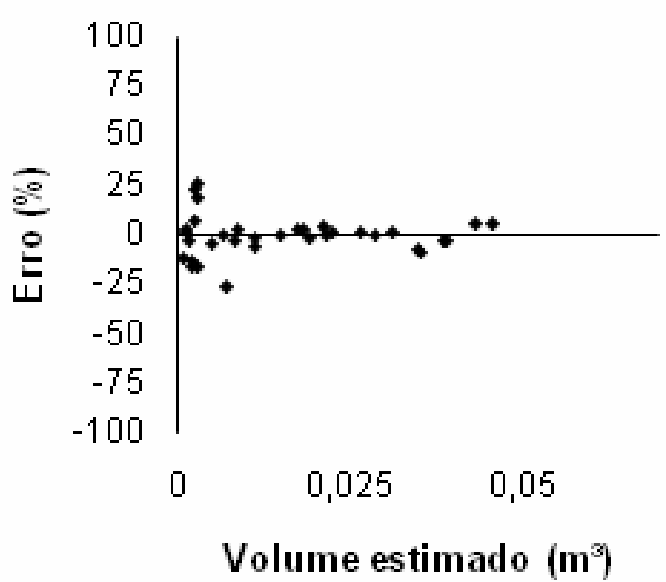

RNA-1

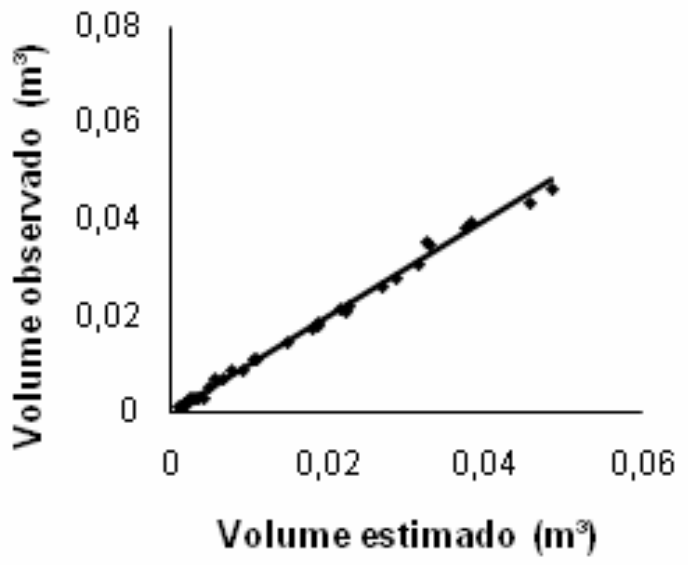

RNA-2

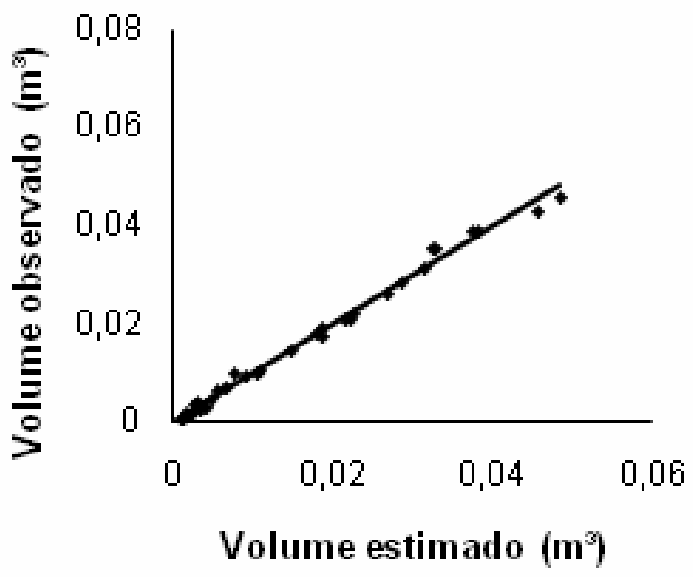

RNA-3

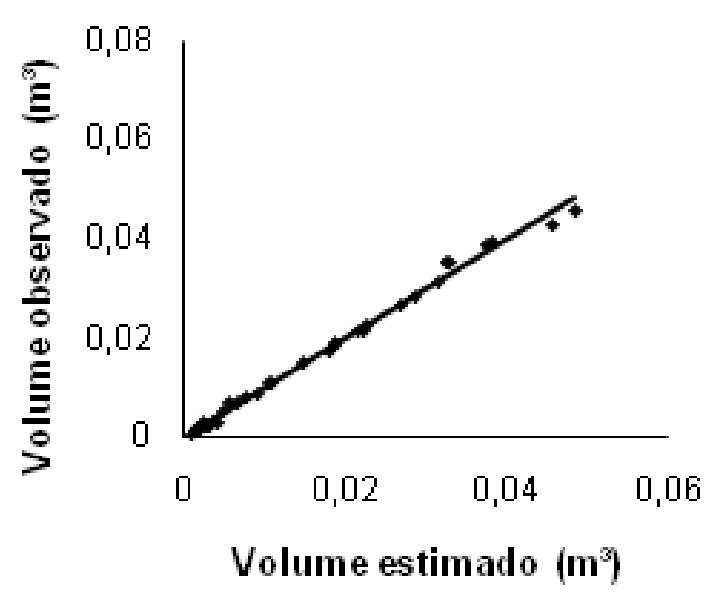


RNA-4

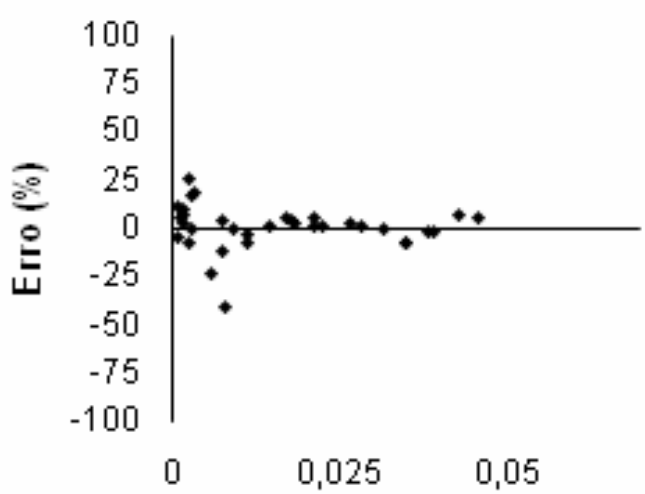

Volume estimado $\left(\mathrm{m}^{3}\right)$

RNA-5

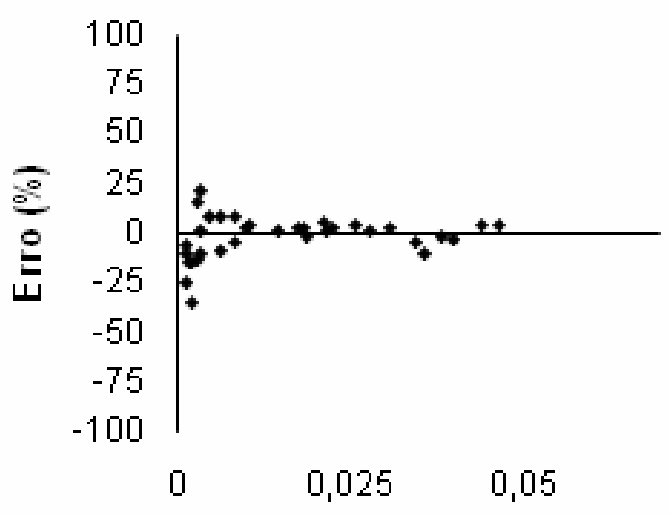

Volume estimado $\left(\mathrm{m}^{3}\right)$
RNA-4

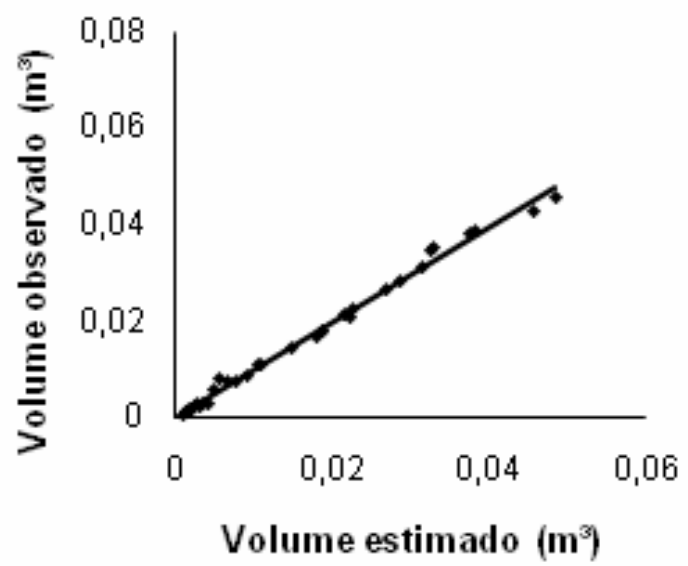

RNA-5

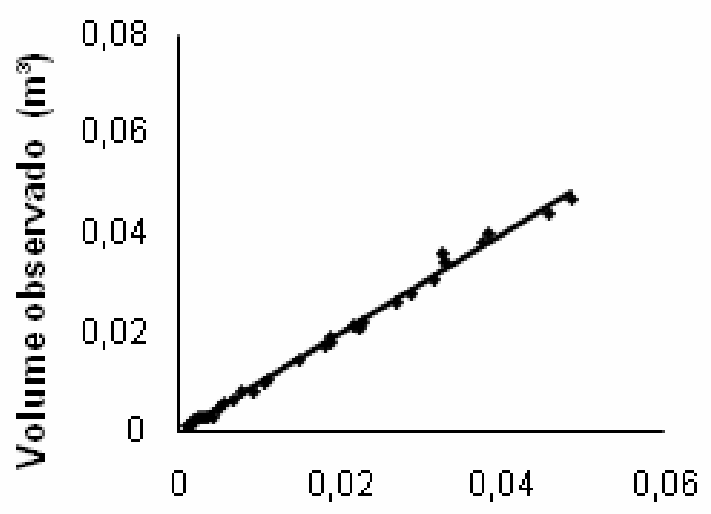

Volume estimado $\left(\mathrm{m}^{3}\right)$

FIGURA 3. Dispersão dos erros percentuais em função dos volumes totais observados para a validação e relação entre valores observados e estimados na validação.

Observa-se através dos gráficos de dispersão que a diferença entre os valores reais e estimados é baixa. Os erros de subestimação e superestimação variaram entre $-42,85$ a $29,13 \%$ respectivamente. Todas as redes subestimaram ou superestimaram os valores para classes de volume menores. Contudo, as cinco redes podem ser utilizadas para estimar o volume do povoamento. O volume total observado para os dados foi $0,537 \mathrm{~m}^{3}$ e o volume total estimado pelas redes variaram entre 0,534 e 0,538 . Estes resultados indicam que os volumes calculados por essas redes são compatíveis com a realidade.

O melhor resultado foi obtido para a RNA-5 que utilizou como arquitetura MLP 2-5-1. Apenas as RNA-3 e RNA-5 não apresentaram distribuição dos resíduos muito dispersas, além disso, a dispersão dos erros não foi tendenciosa. A validação foi feita com a RNA-5 devido ao melhor desempenho do que as outras redes. Na figura 4 estão apresentados os erros percentuais desta rede para a validação. 
RNA-5

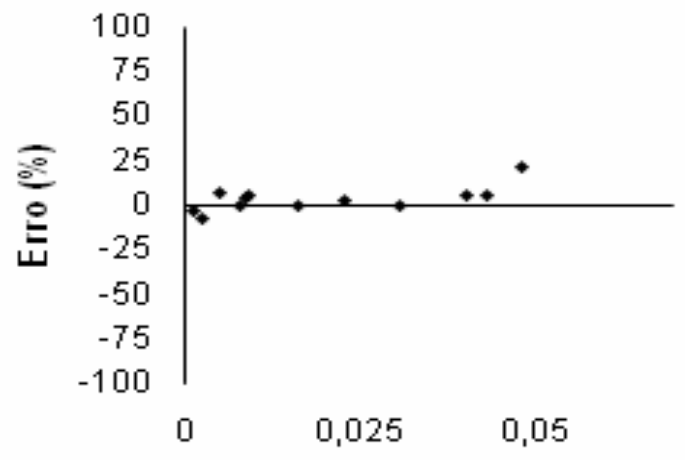

Volume estimado $\left(\mathbf{m}^{3}\right)$
RNA-5

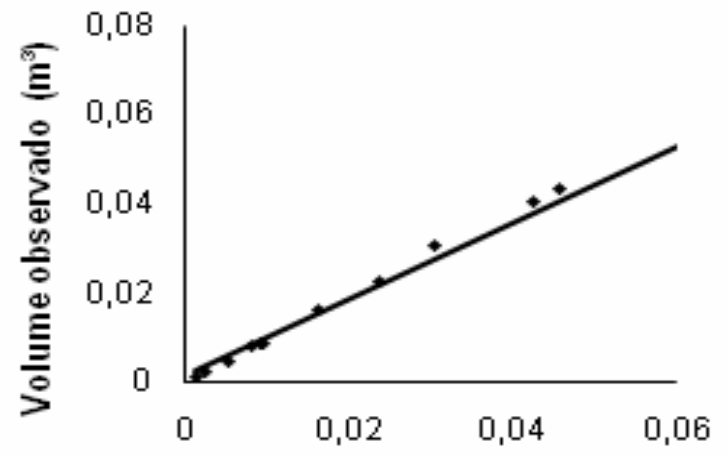

Volume estimado $\left(\mathrm{m}^{3}\right)$

FIGURA 4. Dispersão dos erros percentuais em função dos volumes totais observados para a validação e relação entre valores observados e estimados na validação.

Os dados tiveram bom ajuste para a validação com erros entre $-7,31 \%$ e 20,89\%. Comparando o melhor modelo volumétrico (Schumacher e Hall) com a melhor rede (RNA-5) percebe-se que as distribuições gráficas dos erros em percentagem são semelhantes não apresentando tendenciosidade (Figura 5).

RNA-5

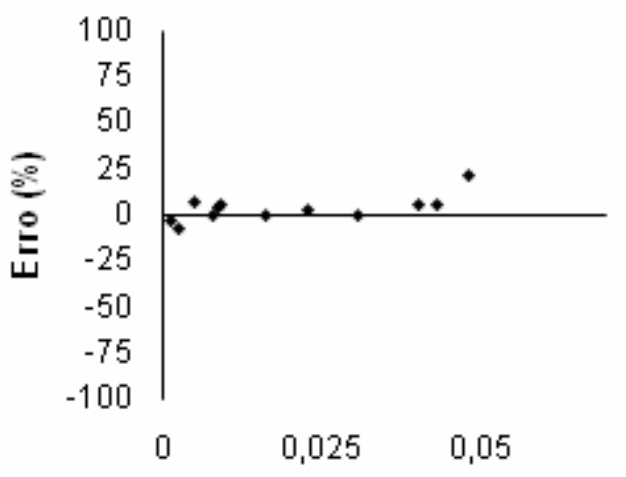

Volume estimado $\left(\mathbf{m}^{3}\right)$
RNA-5

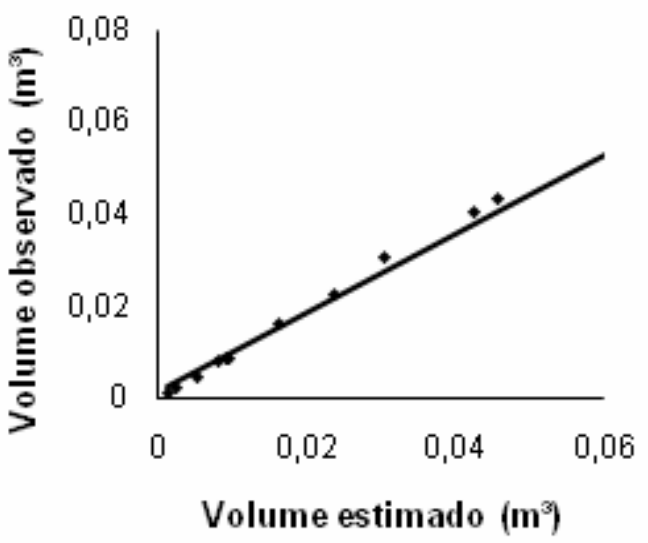

FIGURA 5. Dispersão dos erros percentuais em função dos volumes totais observados.

A análise gráfica dos resíduos mostra que tanto a RNA-5 como o modelo de Schumacher e Hall conseguiram estimar de forma confiável o volume. Todavia, verifica-se através das estatísticas de qualidade ligeira superioridade da RNA em estimar os valores de volume (Tabela 5).

TABELA 5. Estatísticas das estimativas.

\begin{tabular}{cccccc}
\hline & RMSE (\%) & Syx & Syx (\%) & Bias & $\boldsymbol{r}_{\boldsymbol{y} \hat{y}}$ \\
\hline RNA-5 & 4,92 & 0,00077 & 4,92 & 0,00382 & 0,9978 \\
Schumacher e Hall & 5,06 & 0,00085 & 5,06 & 0,00100 & 0,9978 \\
\hline
\end{tabular}


Os valores de RMSE (\%), Syx e Syx (\%) da RNA-5 foram inferiores ao de Schumacher e Hall mostrando melhor precisão. BINOTI et al. (2014) estimando o volume de Eucalyptus spp por meio de configuração de redes neurais artificiais constataram que existe pouca diferença entre o uso de RNA e o modelo de Schumacher e Hall, entretanto mostram a vantagem de utilizar as redes por causa da inclusão de variáveis categóricas.

Diversos trabalhos confirmam a superioridade das RNAs em relação a procedimentos tradicionais no meio florestal. LEAL et al. (2015) registraram melhor desempenho das redes neurais artificiais em relação ao método de regressão, pois estas apresentaram boa adequação aos dados de entrada.

Com os dados do volume real (60 árvores) foi verificado o teste de normalidade Shapiro-Wilk, onde o p-valor foi de 0,0001 evidenciando a não normalidade. Com esse resultado os dados da validação do volume real e dos volumes estimados pelo modelo de Schumacher e Hall e pela RNA-5 foram submetidos ao teste de Kruskal-Wallis e da diferença agregada DA (\%) para comparação entre os métodos (Tabela 6).

TABELA 6. Estatísticas de validação, onde $\left(\chi_{2}^{2}\right)$ D.cal = valor calculado segundo teste de Kruskal-Wallis, $\left(x_{2}^{2}\right)$ D.tab = valor tabelado segundo o teste de Kruskal-Wallis, Da (\%) = diferença agregada, ns= não significativo a $5 \%$.

\begin{tabular}{ccccc}
\hline Variável & Da (\%) & $\left(\chi_{2}^{2}\right)$ D.cal & $\left(\chi_{2}^{2}\right)$ D.tab & Resultado \\
\hline $\begin{array}{c}\text { Volume real } \\
\text { RNA-5 }\end{array}$ & 1,9822 & 11,165 & 19,675 & ns \\
\hline $\begin{array}{c}\text { Volume real } \\
\text { Schumacher e Hall }\end{array}$ & 7,4629 & 11,915 & 19,675 & ns \\
\hline $\begin{array}{c}\text { RNA-5 } \\
\text { Schumacher e Hall }\end{array}$ & 5,5916 & 10,415 & 19,675 & ns \\
\hline
\end{tabular}

A comparação mostrou que os valores estimados pelo modelo de Schumacher e Hall e pela RNA-5 foram próximos do volume real não havendo diferença significativa entre as redes neurais e a regressão. Por meio da análise de Kruskal-Wallis ambos os métodos são válidos e não existe diferença estatística entre si. Através da diferença agregada, ambas as técnicas superestimaram o volume, pois apresentaram sinais positivos de DA (\%) (Schumacher e Hall, 7,4629\% e RNA$5,1,9822 \%)$. Contudo, a rede neural artificial superestimou menos do que a regressão.

\section{CONCLUSÃO}

Redes neurais artificiais do tipo MultilayerPerceptron com algoritmo backpropagation e função de ativação logística usando o diâmetro e a altura total da árvore como variáveis preditoras conseguem estimar de maneira precisa o volume de um hibrido de Eucalyptus grandis $x$ urophylla com 23 meses de idade.

O modelo de Schumacher e Hall foi o que melhor se ajustou para o presente trabalho na estimativa do volume, porém as redes neurais artificiais foram melhores do que os modelos convencionais. 


\section{REFERÊNCIA}

BAIMA A. M. V; SILVA, S. M. A; SILVA, J. N. M. A silvicultura tropical na Amazônia: Equações de volume para uma floresta tropical de terra-firme Moju-Pará. Belém: Embrapa Amazônia Oriental. DFID,p.367-392, 2001.

BINOTI, M. L. M. S; BINOTI, D. H. B; LEITE, H. G. Aplicação de redes neurais artificiais para estimação da altura de povoamentos equiâneos de eucalipto. Revista Árvore, Viçosa-MG, v.37, n.4, p.639-645, 2013. Disponível em: http://www.scielo.br/scielo.php?script=sci_arttext\&pid=S0100-67622013000400007 DOI: http://dx.doi.org/10.1590/S0100-67622013000400007

BINOTI, D. H. B; BINOTI, M. L. M.S; LEITE, H. G. Configuração de redes neurais artificiais para estimação do volume de árvores. Ciência da Madeira (Braz. J. Wood Sci.), Pelotas, v.5, n.1, p.58-67, 2014. Disponível em: https://periodicos.ufpel.edu.br/ojs2/index.php/cienciadamadeira/article/view/4067/321 1. DOI: $10.12953 / 2177-6830 . v 05 n 01$ a06

BINOTI, M. L. M. S; LEITE, H. G; BINOTI, D. H. B; GLERIANI, J. M. Prognose em nível de povoamento de clones de eucalipto empregando redes neurais artificiais. CERNE, Lavras, v. 21, n. 1, p. 97-105, 2015. Disponível em: http://www.scielo.br/scielo.php?script=sci_arttex\&pid=S104-77602015000100097. DOI: http://dx.doi.org/10.1590/0104776020152101115397.

CAMPOS, J. C. C.; LEITE, H. G. Mensuração florestal: perguntas e respostas, 3. ed. Viçosa: UFV, 2009.

FERNANDES, L. M. Estudo da rentabilidade e risco da produção de eucalipto para energia em Minas Gerais. Informações econômicas, SP, v.43, n.6, 2013.

Disponível em: ftp://ftp.sp.gov.br/ftpiea/publicacoes/ie/2013/tec3-1213.pdf

GÖRGENS, E. B; LEITE, H.G; SANTOS, H.N; GLERIANI, J. M. Estimação do volume de árvores utilizando redes neurais artificiais. Revista Árvore, v.33, n.6, p.1141-1147, 2009. Disponível em: http://www.scielo.br/scielo.php?script=sci_arttext\&pid=S0100-67622009000600016. DOI: http://dx.doi.org/10.1590/S0100-67622009000600016

HAYKIN, S. Redes neurais: princípios e prática. 2.ed. Porto Alegre: Bookman, p. 898, 2001.

HORKIN, K; STINCHCOMBE, M; WHITE, H. Multilayer feed foward network are universal approximators. Neural Networks, Bandera, v.2, n.5, p. 359-366, 1989. Disponível em: http://www.sciencedirect.com/science/article/pii/0893608089900208 DOI: http://dx.doi.org/10.1016/0893-6080(89)90020-8

INDÚSTRIA BRASILEIRA DE ÁRVORES (IBÁ). Relatório IBÁ - 2015. Indicadores de desempenho do setor nacional de árvores plantadas referentes ao ano de 2014. Disponível em: http://iba.org/images/shared/iba_2015.pdf. 
LEAL, F. A; MIGUEL, E. P; MATRICARDI, E. A. T; PEREIRA, R. S. Redes neurais artificiais na estimativa de volume em um plantio de eucalipto em função de fotografias hemisféricas e número de árvores. Revista Brasileira de Biometria, São Paulo, v.33, n.2, p.233-249, 2015.

Disponível

em:

http://jaguar.fcav.unesp.br/RME/fasciculos/v33/v33_n2/indice_v33_n2.php

LIBANO, A.M; FELFILI, J. M. Mudanças temporais na composição florística e na diversidade de um Cerrado sensu stricto do Brasil Central em um período de 18 anos (1985-2003). Acta Botanica Brasílica, 20, p. 927-936, 2006. Disponível em: http://www.scielo.br/scielo.php?script=sci_arttext\&pid=S0102-33062006000400016.

DOI: http://dx.doi.org/10.1590/S0102-33062006000400016

MARTINS, E. R; BINOTI, M. L. M. S; LEITE, H. G; BINOTI, D. H. B; DUTRA, G. C. Configuração de redes neurais artificiais para estimação do afilamento do fuste de árvores de eucalipto. Revista Brasileira de Ciências Agrárias, Recife, v.11, n.1, p.33-38, 2016. Disponível em: http://www.agraria.pro.br/ojs2.4.6/index.php?journal=agraria\&page =article\&op=view\&path\%5B\%5D=agraria_v11i 1a5354\&path\%5B\%5D=4884. DOI:10.5039/agraria.v11i1a5354.

MIGUEL, E.P; CANZI, L.F; RUFINO, R.F; SANTOS, G.A. Ajuste de modelo volumétrico e desenvolvimento de fator de forma para plantios de Eucalyptus grandis localizados no município de Rio Verde - GO. Enciclopédia Biosfera Centro Científico Conhecer - Goiânia, v. 6, n.11, 2010. Disponível em: http://www.conhecer.org.br/enciclop/2010c.htm.

MIGUEL, E. P; LEAL, F. A. Seleção de Equações Volumétricas para a Predição do Volume Total de Eucalyptus urophylla S. T. Blake na Região Norte do Estado de Goiás. Enciclopédia Biosfera, Centro Científico Conhecer - Goiânia, v. 8, n. 14, p. 1372-1386, 2012.

Disponível em: http://www.conhecer.org.br/enciclop/2012a/ambien.htm

MIGUEL, E. P; LEAL, F. A; ONO, H. A LEAL, U. A. S. Modelagem na predição do volume individual em plantio de Eucalyptus urograndis. Revista Brasileira de Biometria, São Paulo, v.32, n.4, p.584-598, 2014.Disponivel em: http://jaguar.fcav.unesp.br/RME/fasciculos/v32/v32_n4/indice_v32_n4.php

MIGUEL, E.P; REZENDE, A.V; LEAL, F.A; MATRICARDI, E. A. T; VALE, A.T; PEREIRA, R. S. Redes neurais artificiais para a modelagem do volume de madeira e biomassa do cerradão com dados de satélite. Pesquisa agropecuária brasileira, Brasília, v.50, n.9, p.829-839, 2015. Disponível em: http://www.scielo.br/scielo.php?script=sci_arttext\&pid=S0100-204X2015000900829. DOI: http://dx.doi.org/10.1590/S0100-204X2015000900012.

MIGUEL, E. P; MOTA, F. C. M; TÉO, S. J; NASCIMENTO, R. G. M; LEAL, F. A; PEREIRA, R. S; REZENDE, A. V. Artificial intelligence tools in predicting the volume of trees within a forest stand. African Journal of Agriculture Research, v. 11, p. 1914-1923, 2016.2 Disponível em: http://www.academicjournals.org/journal/AJAR/article-full-text-pdf/A2EFD2958715. 
DOI: 10.5897/AJAR2016.11015.

NIMER, E. Climatologia do Brasil. IBGE, Departamento de Recursos Naturais e Estudos Ambientais. Rio de Janeiro, p.422, 1989.

SALES F. C. V; SILVA, J. A. A; FERREIRA, R. L. C; GADELHA, F. H. L. Ajuste de modelos volumétricos para o clone Eucalyptus grandis $\times E$. urophylla cultivados no agreste de Pernambuco. Floresta, Curitiba, PR, v. 45, n. 4, p. 663 - 670, 2015. Disponível em: https://www.researchgate.net/publication/287975517. DOI: 10.5380/rf.v45i4.37594.

SCHUMACHER, F; HALL, F. Logarithmic expression of timber-tree volume. Journal of Agricultural Research, Washington, v. 47, n. 9, p. 719-734, 1933.Disponível em: https://naldc.nal.usda.gov/download//ND43968352/PDF.

SILVA, A. J; SILVA FILHO, J. L. F; SILVA, M. D. T. da; ROQUE, C. G; CUNHA, F. F. da. Ajuste de modelos hipsométricos e volumétricos para três clones de Eucalyptus em Mineiros - GO. Nucleus, v.12, n.2, 2015. Disponível em: http://www.nucleus.feituverava.com.br/index.php/nucleus/article/view/1372/1911.

DOI: 1982.2278 .1372

STATSOFT, INC. Statistica (Electronic Statistics Textbook.), Tulsa, OK, 2013.

XAVIER, A. E. Uma função de ativação para Redes Neurais Artificiais mais flexível e poderosa e mais rápida. Learning and Nonlinear Models - Revista da Sociedade Brasileira de Redes Neurais (SBRN), v. 1, n. 5, p. 276-282, 2005.Disponível em: http://abricom.org.br/Inlm/publicacoes/vol3-no1/vol3-no1-art1/. DOI: 10.21528/lmlnvol3-no1-art1 